\title{
Effect of Host Plants on The Reproductive Aspects of Cheilomenes Sexmaculata (Fabricius) (Coleoptera: Coccinellidae)
}

\author{
Rakhshan* and Equbal Ahmad \\ Aphid Systematics and Bio-control Laboratory, University Department of Zoology, India
}

Received: 眥July 12, 2018; Published: 眥July 27, 2018

*Corresponding author: Rakhshan, Aphid Systematics and Bio-control Laboratory, University Department of Zoology, TM Bhagalpur University, Bihar, India

\begin{abstract}
The feeding and reproductive potential of predators are greatly influenced by plants due to direct effect on prey quality. Aphis craccivora Koch (Hemiptera: Aphididae) is a sap sucking insect and one of the major pests on economically important crops in India. The lady beetle Cheilomenes sexmaculata is a very common predator of A. craccivora. Hence, the influence of four host plants belong to family Fabaceae viz., Phaseolus sinensis, Lablab purpureus, Vigna radiata and Vigna mungo on the reproductive aspects of $C$. sexmaculata on A. craccivora was investigated. The effect of these host plants was observed significant. The maximum period of preoviposition ( $4.66 \pm 0.33$ days), oviposition ( $33.33 \pm 0.42$ days) and post-oviposition ( $5.66 \pm 0.21$ days) were observed on P. sinensis but its minimum period of pre-oviposition ( $3.66 \pm 0.21$ days), oviposition ( $28.33 \pm 0.71$ days) and post-oviposition ( $4.33 \pm 0.33$ days) were recorded on $V$. mungo. Similarly, the maximum fecundity was observed on $P$. sinensis (510.8 \pm 0.16 eggs) followed by $L$. purpureus (485.0 \pm 3.77 eggs), $V$. radiata (411.9 \pm 5.03 eggs) and $V$. mungo (382.7 \pm 4.92 eggs). The high viability of eggs was also observed on P. sinensis $(85.40 \%)$ and L. purpureus $(81.13 \%)$. Thus, it is concluded that $P$. sinensis is more suitable host plant when preyed on $A$. craccivora and it can be used for mass rearing programme of $C$. sexmaculata due to its high reproductive capacity.
\end{abstract}

Keywords: Cheilomenes sexmaculata; Aphis craccivora; Fecundity; Eggs viability; Host plants

\section{Introduction}

Biological control is considered as the backbone of Integrated Pest Management Programme and about 90\% of all potential pests are already under Biological Control [1]. Biological Control is an important tool of Integrated Pest Management which is method of controlling pest population by using natural enemies. Biological agents are directly influenced by plants as they affect the prey quality [2]. Prey quality has a direct impact on the growth, development and reproduction of predatory insects. The suitability of prey species can be evaluated by measuring its effect on biological attributes of the predator $[3,4]$. Studies on chemical ecology of host plants selection by herbivores have been largely carried out to explain the diversity of secondary plant chemicals and host specialization of herbivores [5]. Allelochemicals and secondary metabolites of host plants can make prey less suitable and decrease fecundity [6], and long-term co-evolution between predators and prey can lead to the development of better adapted strategies for optimal use of a specific prey $[7,8]$.
Aphis craccivora Koch (Hemiptera: Aphididae) is a sap sucking insect and one of the major pests on economically important plants. Coccinellids beetles are a great economic important in agroecosystem of northeast Bihar [9]. The study of literature reveals that age-specific fecundity of Coccinellids has been studied worldwide [10-13] but little is known how host plant affect third tropic level $[6,14]$. Cheilomenes sexmaculata (Coleoptera: Coccinellidae) is an important predator of aphids. Several parameters of effect of host plants have been studied on growth, development, predatory potential and seasonal association of C. sexmaculata [15-17]. The main aim of this study was to investigate the effect of four host plants (Phaseolus sinensis, Lablab purpureus, Vigna radiata and Vigna mungo) on pre oviposition, post oviposition, fecundity and egg viability of $C$. sexmaculata preyed on $A$. craccivora in laboratory at room temperature.

\section{Materials and Methods}

The culture of larvae and adults of C. sexmaculata was maintained separately in the laboratory reared on A. craccivora on 
different host plants viz., $P$. sinensis, $L$. purpureus, $V$. radiata and $V$. mungo. Ten mating pairs of newly emerged beetles were collected from the stock culture and reared on aphids on its host plant in separate beaker $(25 \mathrm{~cm} \times 10 \mathrm{~cm})$ at room temperature $\left(19.45 \pm 0.55^{\circ} \mathrm{C}\right.$ and $60.85 \pm 1.015 \% \mathrm{RH})$. The blotting paper was placed in the bottom of beaker and top was covered by muslin cloth. Fresh aphids were collected daily from experimental field and supplied as food to avoid contamination. The pairs were kept together till the death. Fresh eggs laid by beetles for 24 hours were counted and kept in separate glass Petri dishes of each host plant to avoid desiccation till hatching of the eggs. The pre-oviposition, oviposition and postoviposition periods of female beetles were recorded. The fecundity and egg hatchability (\%) were also recorded. The data was analyzed statistically by using Analysis of Variance (ANOVA).

\section{Results and Discussion}

Table 1: Reproductive aspects of $C$. sexmaculata fed on A. craccivora reared on different host plants (means $\pm S E$ ).

\begin{tabular}{|c|c|c|c|c|c|}
\hline $\begin{array}{c}\text { Host plants/ Reproductive } \\
\text { parameters }\end{array}$ & $\begin{array}{c}\text { Pre-oviposition } \\
\text { period (days) }\end{array}$ & $\begin{array}{c}\text { Oviposition period } \\
\text { (days) }\end{array}$ & $\begin{array}{c}\text { Post-oviposition } \\
\text { period (days) }\end{array}$ & $\begin{array}{c}\text { Fecundity (No. of } \\
\text { eggs) }\end{array}$ & Egg hatching (\%) \\
\hline P. sinensis & $4.66 \pm 0.33$ & $33.33 \pm 0.42$ & $5.66 \pm 0.21$ & $510.8 \pm 4.69$ & $85.40 \%$ \\
\hline L. purpureus & $4.50 \pm 0.34$ & $31.33 \pm 0.61$ & $5.5 \pm 0.22$ & $485.0 \pm 3.77$ & $81.13 \%$ \\
\hline V. radiata & $3.83 \pm 0.30$ & $29.12 \pm 0.70$ & $4.66 \pm 0.21$ & $411.9 \pm 5.03$ & $72.55 \%$ \\
\hline V. mungo & $3.66 \pm 0.21$ & $28.33 \pm 0.71$ & $4.33 \pm 0.33$ & $382.7 \pm 4.92$ & $68.80 \%$ \\
\hline
\end{tabular}

The significant effect of four host plants was observed on different reproductive aspects of $\mathrm{C}$. sexmaculata.

Pre-oviposition period. The period between the adult emergence and the first egg deposition is considered as preoviposition period. The pre-oviposition period of $C$. sexmaculata was observed maximum when $A$. craccivora was reared on $P$. sinensis (4.66 \pm 0.33 days) followed by L. purpureus ( $4.50 \pm 0.34$ days) (Table 1 ). The variation in pre-oviposition period of $C$. sexmaculata on different host plants is observed significant by Analysis of variance $(\mathrm{F}=3.88, \mathrm{P}<0.05)$. However, [18] reported more pre-ovipositional period (4.8 \pm 0.73 days) of $C$. sexmaculata on A. craccivora reared on cowpea. [19] observed less pre-oviposition period of $C$. sexmaculata on Rhopalosiphum maidis, Aphis gossypii and Therioapis trifolli at $25^{\circ} \mathrm{C}$ on reared on maize, cotton and alfa respectively.

\section{Oviposition period}

Oviposition period is the duration between first and last egg laid. This period was also observed on A. craccivora reared on all four host plants. The significant variation was observed on these aphid host plants by analysis of Variance test $(\mathrm{F}=187.63, \mathrm{P}<0.05)$. The maximum period was observed on P. sinensis $(33.33 \pm 0.42$ days) followed by L. purpureus, V. radiata and V. mungo (Table 1). [19] reported that the oviposition period of $C$. sexmaculata depends upon the aphid species but no work has been done so far by any workers regarding the effect of host plants on C. sexmaculata. Several other workers studied the oviposition period of Adalia bipunctata and Coccinella transversalis and found that host plant can influence the oviposition period of predators $[6,20]$. Thus, it is observed that Coccinellids that fed on prey of high quality have more ovarioles and mature earlier than those fed on poor quality of prey.

\section{Post-oviposition period}

The post oviposition period was also observed maximum on A. craccivora when reared on P. sinensis (5.66 \pm 0.21 days) followed by $L$. purpureus, $V$. radiata and $V$. mungo (Table 1 ). The variation in post oviposition period of $C$. sexmaculata on different host plants is observed significant by ANOVA $(\mathrm{F}=6.62, \mathrm{P}<0.05)$.

\section{Fecundity and hatching rate}

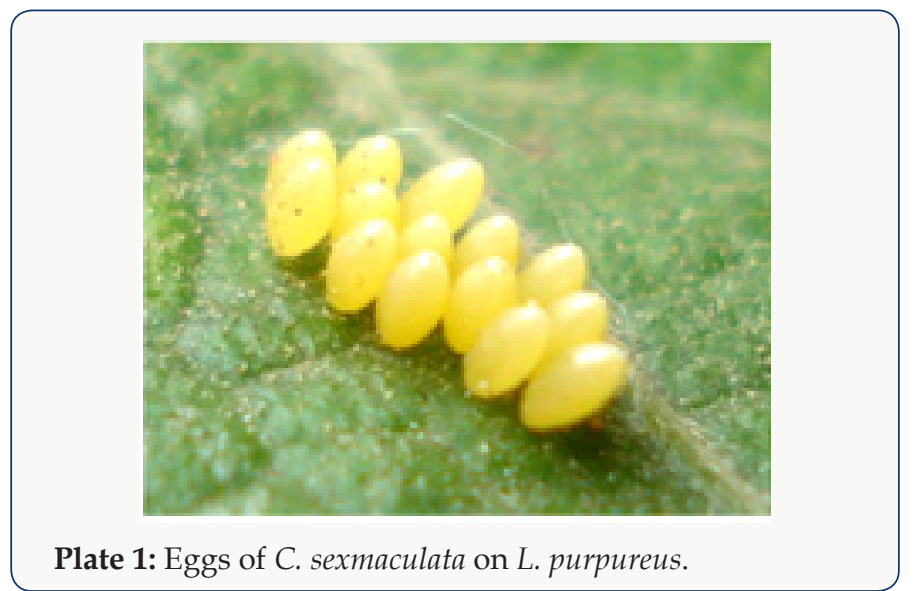

The eggs of $C$. sexmaculata were bright yellowish, cigar shaped with smooth chorion (Plate 1). The eggs turned blackish in color with advancement of age and become completely black before hatching and larvae emerged out from egg shell (Plate 2). The maximum fecundity was observed on P. sinensis $(510.80 \pm 4.69$ eggs) and minimum on $V$. mungo $(382.7 \pm 4.92$ eggs) (Table 1$)$. The maximum eggs hatching was also observed on P. sinensis $(85.4 \%)$ and minimum on $V$. mungo (68.8\%) (Table 1$)$. The variation in the fecundity of $C$. sexmaculata on these host plants is observed statistically significant $(\mathrm{F}=14.73, \mathrm{P}<0.05)$. Similarly, Tank and 
Korat (2007) reported that the female of $C$. sexmaculata deposited $382.7 \pm 16.17$ eggs, and the percentage of hatching was $85.96 \%$, at $20.15 \pm 1.06^{\circ} \mathrm{C}$ on cotton plants. [6,21] also observed that the fecundity and eggs viability of predator varied on different host plants and temperature which is supported to present finding (Figure 1).

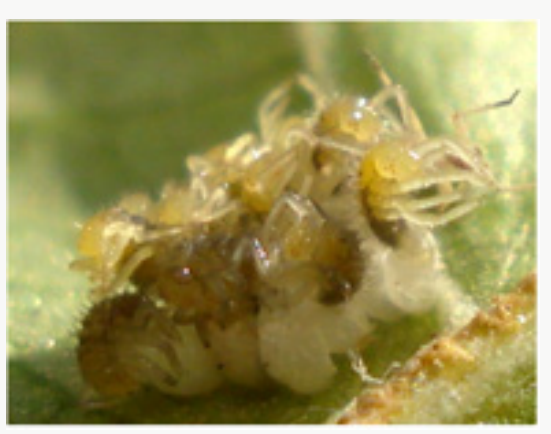

Plate 2: Eggs hatchability of C. sexmaculata.

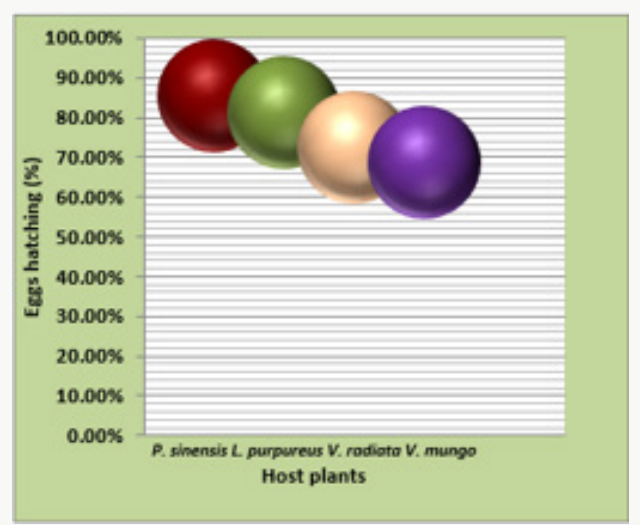

Figure 1: Eggs hatchability (\%) of C. sexmaculata fed on $A$. craccivora reared on different host plants.

The pre-oviposition, oviposition and post-oviposition periods were longest on $P$. sinensis and L. purpureus followed by $V$. radiata and $V$. mungo. This is may be due to allelochemicals components and morphological structure of plants. [22] reported that trichomes of plants influence insect oviposition or feeding in a wide range of insects. Presence of trichomes on the leaves surface also affects the searching efficiency of predator [16,23], which reduced the consumption of aphids resulting low fecundity. C. sexmaculata when preyed A. craccivora fed on P. sinensis and L. purpureus shows maximum fecundity than those fed on $V$. radiata and $V$. mungo. It is clear evidence that quality of food strongly influenced the reproductive aspects of $C$. sexmaculata when reared on different host plants. [8] also reported that food quality directly influenced the development and reproduction of $C$. sexmaculata and Oenopia conglobata.

[24] reported that the even on the peak of her reproductive age, the female ladybeetles fecundity is scarcely affected even if there is a sudden decrease in the quantity of aphid prey. Reproduction requires high energy resources that are supplied by food, which is a major regulatory factor in reproductive success [25]. Young adults of $C$. sexmaculata were more efficient at converting aphid biomass into eggs. The probability of being alive to reproduce is greater in younger than in older females. The daily oviposition rate increases with age until a peak is obtained and then declines on further aging [26]. The present investigation is in conformity of some other authors [24,27-29].

\section{Conclusion}

Studies of prey suitability are needed to develop efficient mass rearing programme for generalist predators and to understand their potential contribution to better integrated pest management. Present results indicate the use of mass production of $C$. sexmaculata especially on host plant $P$. sinensis found to be suitable. This study might result in the development of management tactics for biological control programme.

\section{Acknowledgement}

We wish to thank the Head, P. G. Department of Zoology, T M Bhagalpur University, Bhagalpur for providing Laboratory facilities. We are also thankful to Department of Science and Technology (DST), New Delhi for providing financial assistance through Innovation in Science Pursuit for Inspired Research (INSPIRE) fellowship to the first author.

\section{References}

1. Debach P, Rosen D (1991) Biological Control by Natural Enemies. Cambridge Univ. Press, Cambridge, UK.

2. Vet LEM, Dicke M (1992) Ecology of info chemical use by natural enemies in a tropic context. Annu Res Entomol 37: 141-172.

3. Kalushkov P, Hodek I (2001) New essential aphid prey for Anatis ocellata and Calvia quatuoredecimguttata (Coleoptera: Coccinellidae). Biocontrol Sci Technol 11: 35-39.

4. Kumar S, Ahmad ME, Rakhshan (2016) Influence of prey species on feeding preference, postembryonic development and life span of Cheilomenes sexmaculata (Fabricius). European Scientific Journal 12(36): 403-410.

5. Dicke (2000) Chemical ecology of host plant selection by herbivores arthropods: a multitropical perspective. Biochemical systematic and ecology 28: 601-617.

6. Francis F, Haubruge E, Defrance T, Gaspar C (2001) Effect of aphid host plant on development and reproduction of the third trophic level, the predator Adalia bipunctata (Coleoptera: Coccinellidae). Environ. Entomol 30(5): 947-952.

7. Abrams PA (1986) Adaptive responses of predators to prey and prey to predators: The failure of the arms- race analogy. Evolution 40(6): 12291247.

8. Mirhosseini MM, Hosseini MR, Jalali MA (2015) Effect of diet on development and reproductive fitness of two predatory Coccinellids (Coleoptera: Coccinellidae). Eur J Entomology 112(3): 446-452.

9. Ahmad ME, Kumar S, Parween N, Rakhshan (2012) Screening of Aphidophagous Coccinellids (Coleoptera: Coccinellidae) from Northeast Bihar. J Adv Zoology 33(2): 103-112. 
10. Omkar, Pervez A (2000) Biodiversity is predaceous Coccinellids (Coleoptera: Coccinellids) in India- A review. J Aphidol 14: 41-66.

11. Omkar, Mishra G (2005) Preference-performance of a generalist predatory ladybird: A laboratory study. Biological Control 34(2): 187195.

12. Madahi K, Shragard A, Hossieni R (2013) Prey density dependent life table of Aphidoletes aphidomyza Rondani (Dip, Cecidomyiidae) feeding on Aphis craccivora Koch (Hemiptera: Aphididae) under laboratory conditions. Journal of Plant Protection and Research 53(3): 253-262.

13. Priyadarshani TDC, Hemachandra KS, Sirisena UGAI, Wijayaguasekara (2016) Developmental Biology and feeding Efficiency of Menochilus sexmaculata (Coleoptera: Coccinellidae) (Fabricius) reared on Aphis craccivora (Hemiptera: Aphididae) (Koch). Tropical Agriculture Research 27(2):115-122.

14. Ali A, Ehsan H, Rehman A, Javed K, Gillani A, et al. (2012) Biological parameters and predatory potential of Menochilus sexmaculatus Fab. (Coleoptera: Coccinellidae) at varying temperature on Rhopalosiphum padi L. Pakistan J Agric Res 25(4): 318-322.

15. Rakhshan, Ahmad ME (2015a) Influence of host plants on the growth and development of Cheilomenes sexmaculata (Fabricius) (Coleoptera: coccinellidae) prey on Aphis craccivora Koch. International Journal of Science and Research 438(5): 250-254.

16. Rakhshan, Ahmad ME (2015 b) Predatory efficiency of Cheilomenes sexmaculata (Fabricius) (Coleoptera: Coccinellidae) against Aphis craccivora Koch on various host plants of family fabaceae. European Scientific Journal 11(18): 154-161.

17. Rakhshan, Md Equbal Ahmad (2017) Association of Aphis craccivora Koch infesting Phaseolus sinensis and Lablab purpureus with its predator Cheilomenes sexmaculata (Fabricius) in different seasons. Journal of Entomology and Zoology Studies 5(4): 1222-1228.

18. Pandi PGG, Paul B, Vivek S, Shankarganesh K (2012) Feeding potential and biology of Coccinellid predator Cheilomenes sexmaculata (Fabricius) (Coleoptera) on aphid hosts. Indian Journal of Entomology 74(4): 388-399.
19. Tank BD, Korat DM (2007) Biology of Ladybird Beetle, Cheilomenes sexmaculata (Fab.) in Middle Gujarat Conditions Karnataka J Agric Sci 20(3): 634-636.

20. Shukla A, Jadhav DS (2014) Biology of Coccinella transversalis (Fabricius) on Different aphid species. The Bioscan 9(1):17-22.

21. Jalali MA, Michaud JP (2012) Aphid-plant interactions affect the suitability of Myzus spp. as prey for the two spot ladybird, Adalia bipunctata (Coleoptera: Coccinellidae). European Journal of Entomology 109(3): 345-352.

22. Lewin DA (1973) The role of trichomes in plants defence. Q Rev Biol 48(1): 3-15.

23. Werker E (2000) Trichome diversity and development. Adv Bot Res 31: 1-35.

24. Omkar, Pervez A (2002) Influence of temperature on age-specific fecundity of the ladybeetle Micraspis discolor (Fabricius). Insect Sci Applic 22(1): 61-65.

25. Houck M (1991) Time and resource partitioning in Stethorus punctum (Coleoptera: Coccinellidae). Environ Entomol 20(2): 494-497.

26. Dixon AFG (2000) Insect predator Prey dynamics: Ladybeetles and biological control. Cambridge University Press, Cambridge, England.

27. Stearns SC, Koella JC (1986) The evolution of phenotypic plasticity in life history traits: Predictions of reaction norms for age and size at maturity. Evolution 40(5): 893-913.

28. Hodek I, Honek A (1996) Ecology of Coccinellidae. Kluwer Academic Publisher, The Netherlands, 464 pp.

29. Solangi BK, Hulno MH, Baloch N (2007) Biological parameters and prey consumption by zigzag beetle Menochilus sexmaculatus Fab. against Rhopalosiphum maidis fitch, Aphis gossypii glov. and Therioaphis trifolii monell. Sarhad J Agric 23(4):1097-1101.

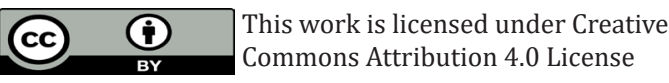

To Submit Your Article Click Here:

Submit Article

DOI: $10.32474 /$ CIACR.2018.03.000175
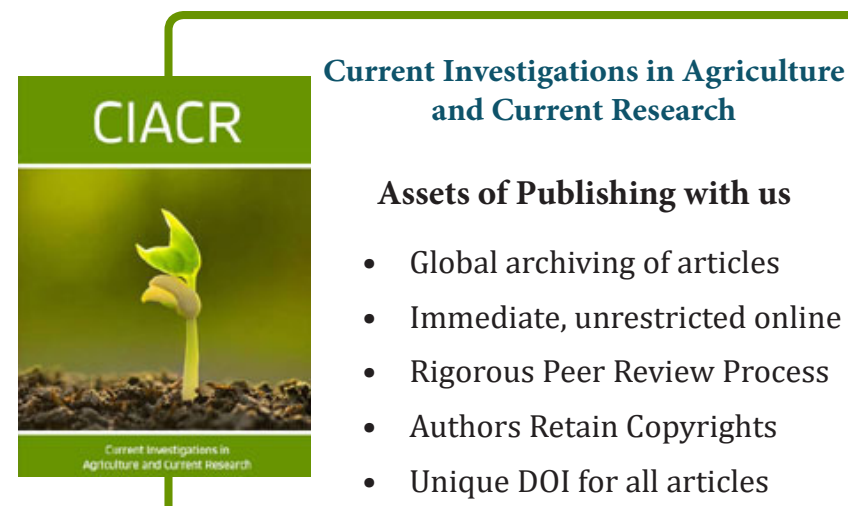

Assets of Publishing with us

- Global archiving of articles

- Immediate, unrestricted online access

- Rigorous Peer Review Process

- Authors Retain Copyrights

- Unique DOI for all articles 